\title{
Determinant of Public Service Innovation Capacity Development in Local Government
}

\author{
R. Slamet Santoso ${ }^{1}$, Hardi Warsono ${ }^{2}$, Retno Sunu Astuti ${ }^{3}$, Ida Hayu Dwimawanti ${ }^{4}$, \\ Kismartini ${ }^{5}$, Zahra Arum Fatimah ${ }^{6}$ \\ \{rssantoso@lecturer.undip.ac.id ${ }^{1}$ \} \\ Universitas Diponegoro, Indonesia ${ }^{1,2,3,4,5,6}$
}

\begin{abstract}
The target of bureaucratic reform is the improvement of public services, in line with the rapidly changing bureaucratic environment that demands more creative and innovative bureaucracies. This research analyzes the processes and determinants of capacity building for public service innovation in local governments. The better capacity for developing public service innovations is a very important factor in the success of bureaucratic reform. This research uses a qualitative method with a literature review approach of various journal publication articles, comparative analysis and formulating results. The main results of this research are strong leadership, policy and resource support, and institutional networks. The capacity of public service innovation guaranteed an improvement of the quality of public services and increasing public satisfaction with the performance of the bureaucracy. The formulation of the determinants of the development of the capacity for innovation in public services, along with the recommendation model proposed, can be used to increase bureaucratic awareness of the importance of an agile and innovative bureaucracy to in order to be a world-class bureaucracy. As a follow-up, it is still necessary to carry out further research, especially related to the aspects of value development or a culture of innovation in the bureaucracy.
\end{abstract}

Keywords: Innovation Capacity, Public Service, Management, Development, Local Government

\section{Introduction}

The public services that are delivered have to get better and better guided by service standards. Public service improvement is increasingly being demanded in line with developments in information and communication technology. Continued efforts to improve conventional services, for example related to coaching and empowerment. Responding to various demands for service quality improvement, public service innovation is a must/obligation. Public service innovation has been raised since 2014, with various public service innovation competitions until now.

The development of public service innovations at this time is still not maximal in terms of regulatory or policy support. Policy or regulatory aspects have a very important role in the government system. Policies or regulations on public service innovation, both at the level of laws and more technically issued by Ministries and Agencies, have yet to be implemented optimally at the practical level at the implementation level. All elements of government institutions should make technical steps, so that innovation policies and regulations at the top level can be translated into services in the field. 
The development of innovation in government circles is constrained by the unclear management of administrative authority, which has an impact on the weak priority of institutional development steps and supporting resources. In principle, the innovation authority must have a special institution that handles, both at the central and local levels, so that all policy steps can be carried out more optimally. The prerequisites for the above conditions also require the priority of institutional development or innovation units in each government organization, at least the authority or innovation focus is inherent as an obligation of every public organization, it turns out that this cannot be found yet, which is still very partial, meaning that it has different steps in each agency. government.

A clear institutional component will be very helpful in institutionalizing the development of innovation in public services, with a lot of support, resources, regulations, and others that will definitely be prepared. Institutional development is the key to the success of developing public service innovations. This institution can give birth to various public service innovations in a sustainable manner, which is aimed at overcoming various service problems for the sake of improving organizational performance.

The value base becomes important when it comes to building a new change. The prochange value is very relevant in the development of public service innovations. Values can become culture, habits change towards improvement is the main target of value change and innovation. In fact, this ideal has not grown much among government organizations, there are still many who are stuttering to respond to change, especially if they are required to be able to apply the value of innovation.

The issue of the value of innovation needs to be possessed by every government apparatus or employee, currently only some of the apparatus are accustomed to innovating, with results that are useful for improving the implementation of duties and services. Usually, those who often do it are those who work in the fields of education and research, but actually it doesn't have to be like that, every apparatus must be able to have the value of innovation and continuously apply it to improve services in their respective workplaces.

The lack of innovation development is largely due to the government's low capacity for innovation, particularly in local governments. Several determinants of government innovation capacity include: (1) lack of specialization and competence of human resources; (2) weak anticipatory attitude and management of bureaucratic change; (3) ineffective decentralization and differentiation and discretion in the implementation of tasks and functions; (4) lack of support for commitment from the leadership or bureaucratic elite to public service innovation, (5) weak internal and external communication and bureaucratic collaboration / network; and (6) not yet optimal policy for developing public service innovation.

\section{Method}

\subsection{Theory}

Public Service Innovations. Public service and innovation are necessity, all public sector entities strive to improve their performance and this can be obtained if innovative thoughts and practices develop in the bureaucracy. As the opinion of Osborne et al. [1], in the article Sustainable Public Service Organization: A Public Service-Dominant Approach, states that there are seven proposals for sustainable public service practices. This proposition has been summarized in the following figure that shows 7 elements for developing a sustainable service organization, namely: SERVICE (System, Engagement, Relationship, Value, Innovation, Co- 
Production, Experience). The fifth proposition specifically places the importance of innovation for public sector organizations. Business growth for public sector organizations is based on innovation - not as a means of achieving competitive advantage but rather as a means of achieving service efficiency and effectiveness.

Innovation Capacity. The capacity to innovate is one of the important differentiating factors among public organizations. Innovation capacity is the ability of an organization to develop comprehensive, systemic and holistic innovations, and involve wider and higher quality participation. An organization with a strong capacity to innovate shows continuous innovation, produces superior results, and encourages social change towards the improvement of life as a whole.

The capacity to innovate can be seen through the condition of the organization in relation to the characteristics of the innovative organization. The nuances of capacity to innovate can be inferred from the characteristics of an innovative organization. There are 3 things related to organizational innovation capacity [2]: (1) The characteristics of an innovative organization; (2) Factors that influence innovation capacity; and (3) Innovation patterns as a reflection of the capacity to innovate.

Bean and Readford [2] suggest that an innovative organizational climate has the following characteristics: (1) mutual trust; (2) Open to new ideas and alternative approaches in solving problems and taking advantage of opportunities; (3) An environment that emphasizes adaptability; (4) Emphasizes flexibility; (5) Targeted with a commitment to the goal; (6) Show concrete evidence that innovation is valued; and (7) Give rewards for innovative achievements.

\subsection{Analysis Technique}

This paper uses a literature review approach to various facts and practical phenomena of implementing public service innovation in local governments in various countries, to then carry out in-depth discussions related to how the determinants of innovation development capacity in Indonesia.

\section{Result and Discussion}

This section will present various views and discussions on the determinants or determinants of the capacity of public service innovation in local government.

\subsection{Previous Research}

Some of the results of previous research that tried to provide insights into the development of public sector innovation and public service innovation in local government, include:

Fisman and Werker [3] in this Innovations in Governance article explored innovations used for investment promotion and growth. Several policymakers and their institutions have determined changes and other influences on regulation. A survey conducted on important innovations in various characteristics of government, it can be concluded that the government has the courage to accumulate capital and build policies based on several principles: competitive pressure, free flow of information, trade in ideas and technology, and the focus of value and cultural transfer. This paper also discusses growth-enhancing governance innovations, which are summarized as follows: (1) Working from within the system, these additional innovations can be divided into five major areas: auditing, ring fencing, change based on norms, media 
pressure, and outsourcing. and (2) Working from outside the system, two different technologies of governance reform by outside actors including aid requirements and between national competitions.

Hennala et al. [4], examined the process of public service innovation involving multiactors. His research entitled: Challenges of Multi-Actor Involvement in the Public-Sector FrontEnd Innovation Processes Constructing an Open Innovation Model for Developing Well-Being Services. Using the concept of innovation, public sector organizations and stakeholders with a constructive research approach and a combination of quantitative and qualitative analysis produce an open innovation model. This open innovation model recognizes primarily the entry of outside information and knowledge from service users that has the potential to generate new and value-added insights into the innovation development process.

Pekkarinen et al. [5] with their book entitled: Clashes as Potential for Innovation in Public Service Sector Reform. Using the concept of innovation and public sector reform with qualitative research methods (case studies and content analysis). The results of his research are to reveal the various pressures that influence the level of innovation and manifest as clashes and become controversies between the old way of thinking and the new way. But they can provide a solid foundation (platform) for innovation to be openly analyzed and facilitated.

Palm and Algehed [6] in the article Exploring Enablers of Innovative Quality Development in Public Administration. The aim of this study is, therefore, to determine empirically which of the various enabling factors for innovation - may be most important for a specific process step for moving from idea to innovation implementation in the context of public administration, and, furthermore, for identify additional enablers for innovation quality development. These factors are presented as empirically identified (research results) enablers for innovation in public administration: (1) Committed and direct leadership; (2) internal and external networks; (3) the innovation process is alternately organized as a separate project and as part of standard operating procedures; (4) understanding of the system, including understanding of how the parts contribute to a common vision; and (5) communication of real short-term (not necessarily substantial) results achieved. Three of these enablers were the one previously identified as the overall enabler for innovation and the two complementary enablers identified earlier.

Osborne et al. [1] in the article Sustainable Public Service Organizations: A Public ServiceDominant approach, the author submits seven proposals for sustainable practice, this proposition has been summarized showing 7 elements for developing an organization sustainable services, namely: SERVICE (System, Engagement, Relationship, Value, Innovation, Co-Production, Experience). The fifth proposition specifically places the importance of innovation for public sector organizations. Business growth for public sector organizations is based on innovation - not as a means of achieving competitive advantage but rather as a means of achieving service efficiency and effectiveness.

The development of innovation is also closely related to the decentralization policy implemented by the central government to local governments, the greater and more extensive the authority given, the greater and wider the role of local governments to take part in developing their potential. Decentralization has given additional responsibilities to regions to be seriously involved directly in developing innovation capacity at the local level.

Based on the studies that have been conducted by several previous researchers as shown, several important conclusions are obtained which are considered relevant to the study to be carried out. Important conclusions from previous studies include: that the study of local government innovation in general can be studied from various perspectives. The various perspectives referred to in previous research are: (a) typology and degree of innovation; (b) the values and culture of innovation; (c) innovation capacity; (d) institutional; (e) political 
leadership and support; (f) involving non-government actors (private and public) in innovation development; (g) the existence of innovation enabler factors, (h) the role of regulations and policies in innovation; (i) elements of innovation; and (j) stages of innovation capacity building.

\subsection{Review}

The issue of capacity is important in the era of governance, as well as what will be the concentration in this research, especially when it is related to the dynamics of information and communication technology developments, the bureaucracy has entered into an era of innovation, an era of disruption that urgently needs the support of bureaucratic innovation capacity. Real innovative governance does not only emphasize the use of new ideas and science alone, but also requires the ability to solve social and economic problems. This innovative government requires several preconditions, such as quality human resources, a dynamic work environment, integration with new knowledge, and collaboration with the community and other stakeholders.

Before diving at a lower level, it is necessary to convey how innovation and governance are one of the determinants of the progress of a nation or country. Kawabata and Camargo [7], stated that innovation is considered as a fundamental key activity to maintain economic growth. More than a combination of efficient production factors or the practical application of some technological invention or innovation can drive the development of new skills and competitive advantage. Innovation has been considered as an important activity for organizations to compete in the modern and international world and dynamic business environment. For nations, innovation is considered as a key activity that is fundamental to maintaining economic growth and a competitive advantage over other countries.

Furthermore, it is stated that there is a relationship between the quality of the institution and the level of innovation activity in several countries. This relationship can show the characteristics of an institution that can enhance innovation. The quality of institutions has been explored in the economic field to explain its relationship to economic growth. On the other hand, in the administration field, innovation has been linked to the competitiveness of companies and business environments.

Public service and innovation are necessity, all public sector entities strive to improve their performance and this can be obtained if innovative thoughts and practices develop in the bureaucracy. As the opinion of Osborne et al. [1], in the article Sustainable Public Service Organization (figure 1): A Public Service-Dominant Approach, states that there are seven proposals for sustainable public service practices. This proposition has been summarized in the following figure which shows 7 elements for developing a sustainable service organization, namely: SERVICE (System, Engagement, Relationship, Value, Innovation, Co-Production, Experience) where the fifth proposition specifically places the importance of innovation for public sector organizations. Business growth for public sector organizations is based on innovation - not as a means of achieving competitive advantage but rather as a means of achieving service efficiency and effectiveness. 


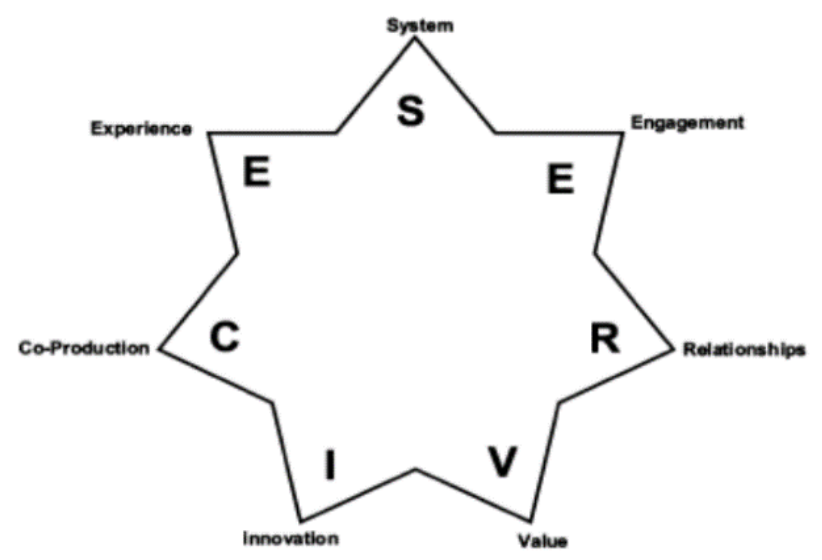

Fig. 1. Service Organization Development Elements.

In the development of public sector innovation, especially in local governance, the innovation capacity factor becomes the determining factor. The ability of local governments to develop innovations as a whole and systemically is crucial. Leaders in this case still play a role in the formation of innovative government, because they are very decisive in making the direction of local policies. On many occasions it is necessary to add clarity over the authority and institutions that are responsible for developing and implementing local innovations. Many institutional forms that are taken are only formality to fulfill regulatory provisions, even though it is not necessary, institutions must be formed with full consideration, given a significant role with clear targets, institutional status also needs to be determined, whether structural or nonstructural. This is still rarely studied.

Another important thing that needs to be considered is the aspect of the innovation climate, until now there has been no concrete form of a climate for innovation development in local governments, it is very difficult to find local governments that have a vibrant and institutional climate of innovation, the climate of innovation is still heavily influenced by the rules and orders of the leadership. Therefore, it is necessary to devise an innovation climate factor based on the internal values of personnel, it is necessary to systematically search, form and develop innovative apparatus.

\section{Conclusion and Recommendation}

The capacity to innovate is one of the important differentiating factors among public organizations. Innovation capacity is the ability of an organization to develop comprehensive, systemic and holistic innovations, and involve wider and higher quality participation. An organization with a strong capacity to innovate shows continuous innovation, produces superior results, and encourages social change towards the improvement of life as a whole. The capacity to innovate can be seen through the condition of the organization in relation to the characteristics of the innovative organization. The nuances of capacity to innovate can be inferred from the characteristics of an innovative organization. There are 3 things related to organizational innovation capacity [2]: (1) Innovative organizational characteristics; (2) Factors affecting innovation capacity; and (3) Innovation patterns as a reflection of capacity to innovate. 
Bean and Readford [8] suggest that an innovative organizational climate has the following characteristics: (1) mutual trust; (2) Open to new ideas and alternative approaches in solving problems and taking advantage of opportunities; (3) An environment that emphasizes adaptability; (4) Emphasizes flexibility; (5) Targeted with a commitment to the goal; (6) Show concrete evidence that innovation is valued; and (7) Give rewards for innovative achievements.

According to Glor's view, an organization with a large capacity for innovation has a space of freedom that is conducive to unlimited creativity, has management capabilities, organizational capabilities that support the alignment of differences. Innovative organizations have increasingly advanced diversity management, deliberately looking for differences and managing them for the greater common good [2].

A public organization in conducting innovation needs to have innovation capacity. According to Bean and Readford [8] in Elu and Purwanto [2], the factors that influence the capacity for innovation are: (1) understanding; (2) Experience; (3) Diversity (diversity); and (4) Skills (skills). Furthermore [2] states that there are 10 variables that have a significant relationship with the innovativeness of government, namely: (1) Specialization that allows a broad knowledge base in gathering ideas; (2) Differentiation between units, which allows to some extent autonomy for innovators and leaders; (3) Professionalism, which increases commitment to change; (4) Decentralization, which provides space for freedom within certain limits; (5) Management attitudes that support change; (6) Technical knowledge; (7) Top-level managers, who provide the necessary resources and coordination; (8) Availability of resources, both funds and human resources; (9) External communication, which allows the organization to get new ideas; and (10) External communication that fosters the dissemination of best practices.

According to Bean and Readford [8], organizational innovation capacity can be traced based on matters related to executives, namely: (1) Personal understanding of the innovation process for executives, can provide guidance and support for innovation development in organizations; (2) Continuous learning and study can make executives an important contributor to the development of organizational innovation; (3) Curiosity, it can be easier to build productive relationships and cooperation with organizational innovators; (4) Openness to criticism and suggestions from anyone; (5) Leadership, which places innovation as part of the development of organizational capabilities; and (6) Gives greater attention to strategic matters than operational ones.

Based on the various factors that determine the capacity for innovation above, it is summarized as follows, including the factors: Mutual trust; The opening of new ideas; Adaptive environment; Flexible organization; Focused on goals and commitment to goals; Rewards for innovation achievements; Encourage all parties to play an active role in innovation; Change the rules of the game and challenge the competition; Appreciate new technology; Provide resources; Individual motivation; Organizational culture; Change challenges; and Factors hindering capacity to innovate.

Finally, the development of public service innovation capacity in local government circles requires a specific determinant of success, which is related to the following matters, namely: clarity of the aspect of authority, the accuracy of developing local innovation-capable institutions, and improving the climate of innovation, which comes from the quality of the apparatus with strength. internal innovative values. These additional determinants will further enhance the innovation capacity of local governments in developing public service innovations.

\section{References}

[1] S. P. Osborne, Z. Radnor, T. Kinder, and I. Vidal, "Sustainable Public Service Organisations: A 
Public Service-Dominant approach," Soc. Econ., vol. 36, no. 3, pp. 313-338, 2014.

[2] W. B. Elu and A. J. Purwanto, Main Material of Innovation and organizational Change. Second Edition. Jakarta: Universitas Terbuka, 2016.

[3] R. Fisman and E. Werker, "Innovations in governance," Innov. Policy Econ., vol. 11, no. 1, pp. 79-102, 2011.

[4] L. Hennala, S. Parjanen, and T. Uotila, "Challenges of multi-actor involvement in the public sector front-end innovation processes," Eur. J. Innov. Manag., 2011.

[5] S. Pekkarinen, L. Hennala, V. Harmaakorpi, and T. Tura, "Clashes as potential for innovation in public service sector reform,” Int. J. Public Sect. Manag., vol. 24, no. 6, pp. 507-532, 2011.

[6] P. Klas and J. Algehed, "Exploring Enablers of Innovative Quality Development in Public Administration," Int. J. Qual. Serv. Sci., vol. 9, no. 2, pp. 203-217, 2016.

[7] M. K. Kawabata and A. S. Camargo Junior, "Innovation and institutions' quality: a comparative study between countries," Int. J. Innov. Sci., 2020.

[8] T. W. Bean and L. P. Stevens, "Scaffolding reflection for preservice and inservice teachers," Reflective Pract., vol. 3, no. 2, pp. 205-218, 2002. 